\title{
Insilico and Proteomic Analysis of Dengue Vector Midgut Proteins Treated by Aegle marmelos Bioactive Compounds
}

\author{
Sugapriya Menaga Paulraj, Maheswaran Baskaran, Sakkanan Ilango, \\ Geetha Paramasivam and Joseph Sebastinraj
}

\begin{abstract}
Dengue disease is a mosquito vector borne viral disease which is transmitted mostly by the Aedes aegypti mosquito vector species. Other viral diseases such as chikungunya, yellow fever and zika are also caused by this vector. After feeding on a DENV-infected person, the virus replicates in the mosquito midgut then it distributes to other tissues. Medicinal plant species contains wide series of phytochemicals such as primary and secondary metabolites that produce biological activities and defenses against mosquitoes. In the current study, a methanol leaf extract of Aegle marmelos was assessed for larvicidal efficacy and midgut alteration of third instar Ae. aegypti larvae. After the larvicidal bioassay, the probit analysis identified Lc50 in this extract that killed the larvae at the concentration of 49 ppm. Proteomic analysis and in-silico studies revealed that the predicted protein could disrupt the larvae midgut because of the Aegle marmelos natural bioactive compounds and secondary metabolites. Our approach is to identify the inhibitor proteins that bound to midgut of Ae. aegypti larvae after treatment with the Aegle marmelos bioactive compounds by using computational proteomic analysis.
\end{abstract}

Index Terms - Dengue, Aedes mosquito, MALDI, midgut \& proteome.

\section{INTRODUCTION}

Dengue, Dengue Shock Syndrome and Dengue Hemorrhagic Fever (DHF) are an important vector borne viral diseases. WHO said the prevalence of dengue has grown-up dramatically worldwide in these decades and the largest number of dengue cases ever reported was in 2019.

\footnotetext{
Manuscript received April, 2020; revised May 2020, and published on June, 2020

Sugapriya Menaga Paulraj \& Sakkanan Ilango, ${ }^{1}$ Post Graduate and Research Department of Zoology,

Maheswaran Baskaran \& Geetha Paramasivam, ${ }^{2}$ Department of Biotechnology, Ayya Nadar Janaki Ammal College (Autonomous), Sivakasi, India.

Joseph Sebastinraj, ${ }^{3}$ Jamal Mohamed College (Autonomous), Tiruchirappalli, Tamil Nadu, India.

Email:menagadurai@gmail.com
}

There are 2.5 billion people Worldwide are at risk of dengue fever (Guzman et al., 2010). In India, a sum of 136,422 cases and 132 deaths were recorded in 2019 which is the maximum number of cases when compared to previous year. Dengue virus contains, four serotypes are DENV1, DENV2, DENV3 and DENV4 and also several subtypes. One serotype can produce lifelong immunity but it is merely a partial immunity besides the other serotypes of reinfection. All these serotypes have interaction with the host and displayed unique features based upon its response (Ekta and Neha, 2014). The structural features of these virus comprises of three structural proteins such as capsid, membrane and envelope and seven (NS1, NS2A, NS2B, NS3, NS4A, NS4B and NS5) non-structural proteins.

World's insecticide market of phytochemicals was reported as one per cent (Ghosh et al., 2012). Phytochemicals may help as these are relatively safe, cheap, environment friendly, biodegradable and readily available in all over the world. Controlling this medically important vector is really a challenge of emerging resistance to chemical pesticides. Medicinal plants contain a wide variety of phytochemicals such as alkaloids, polyines, coumarins, peptides, flavonoids, terpenoids, polyphenolics and saponins that have demonstrated therapeutic effect against a wide range of viruses, their entry and replication (Idrees and Ashfaq, 2013).

The plant Aegle marmelos belongs to Rutaceae family, also known as bael, a spiny tree. Native to India, it is an important medicinal herb and widely used in medicinal systems (Atul, 2012). These plants consists various phytochemicals and are responsible for its medicinal value. Hence this study, aims at investigating the larvicidal efficacy of the leaves methanol extract of Aegle marmelos on the III instar Ae. aegypti larvae. Bradford method was used to estimate the infected gut protein concentrations (Stephenson, 2010). Further the plant extract that exhibits larvicidal activity was used to study proteomic analysis of the larvae midgut and its related proteins were predicted by computational analysis. We have isolated the protein present in 
mosquito midgut using SDS-PAGE after intoxication of Ae. aegypti larvae with plant extract Aegle marmelos to discover novel inhibitor proteins. In this contest, proteomics analysis might be very useful for the identification and development of new drug targets to advance the insecticide resistance on midgut larvae.

The proteomic analysis was conducted to find Ae. aegypti midgut proteins after intoxicated with the plant extract with the help of Mass spectrometry (Whiten et al., 2018). Our approach combined with SDS PAGE and MALDI to identify the DENV inhibitor proteins that interacted with the Ae. aegypti midgut.

\section{Material AND Methods}

\section{1) Plant Material Collection and Extraction}

The studied plant leaves of Aegle marmelos was freshly collected from Sivakasi, Viudhunagar District in the state of Tamil Nadu, India. The studied plant was identified with voucher specimen. The leaf samples were washed and rinsed thrice with sterile water to remove the contaminants and then shade dried at room temperature to remove the moisture. Then, the dried samples were made into fine powder. The fine powders were extracted twice with $95 \%$ methanol solvent in Soxhlet apparatus, to obtain the phytochemicals. The extract was then concentrated under reduced pressure in the rotary vacuum evaporator until the solvents evaporated completely at $45^{\circ} \mathrm{C}$ to get semisolid mass of crude extracts and then freeze dried at $-80^{\circ} \mathrm{C}$ to obtain solid residue (George, 2008).

\section{2) Larvae Collection \& Larvicidal bioassay}

The mosquito larvae (Aedes aegypti) were collected from the Indian Council of Medical Research (ICMR), Madurai, Tamil Nadu and India. Mosquito culture was maintained at the temperature of 28 to $29^{\circ} \mathrm{C}$, 80 to $85 \%$ relative humidity under the light: dark photoperiod cycle of 14:10 $\mathrm{h}$. The larvae were reared in plastic tray containing tap water and fed brewer's yeast and $\operatorname{dog}$ biscuits powder in the ratio of 1:2. The water has been changed on each alternate day.

According to the guidelines of World Health Organizationm, the larvicidal bioassay was performed on third instar larvae (WHO, 2005). To $150 \mathrm{ml}$ of de-chlorinated tap water taken in a beaker appropriate volume of $1 \%$ stock solution of Aegle marmelos methanol extract fractions were added and mixed to obtain different concentrations. Third instar larvae of Ae.aegypti in 25 numbers were released to each concentration and provided with larval feed and test was conducted in five replicates. There are two controls were maintained (one with $150 \mathrm{ml}$ water alone and the other with $150 \mathrm{ml}$ of water containing maximum volume of acetone in the test sample). Primary larvicidal screening was carried out with $100, \quad 500 \& 1000$ ppm concentrations to identify the active range for the further bioassay with the extract. Afterwards of the preliminary analysis, a test range of 50,100, 150, 200 and $250 \mathrm{ppm}$ were fixed to identify the Lc50 and Lc90 values and outright of per cent mortality recorded after 24 and $48 \mathrm{hrs}$ of exposure.

\section{3) Statistical Data analysis}

Considering the percentage mortality of the larvae after 24 and $48 \mathrm{hrs}$ in different concentrations, Lc50 of the test fractions, we calculated using probit analysis and IBM SPSS Statistics 23 software. Per cent mortality was calculated based on the Abbott's formula (Abbott, 2010) and the statistical analysis was carried out based on the log-dose response (Finney, 1971). The significant difference in Lc50, Lc90, and 95\% Fiducial limits and also the slope values are calculated.

\section{4) Preparation of midgut protein extracts}

In this study, the proteomic study on the third instar larvae of Aedes aegypti mosquito vector was carried out after intoxication with various concentration of Aegle marmelos methanol extract for 24 and $48 \mathrm{hr}$ period. After $48 \mathrm{hr}$ the dead larvae from the treatment were collected. For the midgut sample preparation of SDS, larvae midguts were collected under a microscope by dissection using ER Buffer consist of protease inhibitor in the conc. of $1 \mu \mathrm{L} / \mathrm{mL}$ (Sigma P9599) (English and Reddy, 1989). The midgut was completely separated from other mosquito parts by standard procedure (Butler and Deana, 2014). Centrifugation of midgut sample was done at 12,000 rpm for 15 mins at ice cold condition. In to new eppendorf tubes the supernatants were collected and stored in $-80^{\circ} \mathrm{C}$ till further electrophoretic analysis. The photographs of both control and tested larvae midgut was captured in the light microscope attached with a digital camera. Protein concentration in the midgut was estimated by Bradford assay which was compared with standard BSA protein (Bradford, 1976).

\section{5) Protein profiling}

SDS-PAGE analysis of both the control and treated Aedes midgut larvae extract was performed by using the standard protein isolation (Laemmli, 1970). For sample preparation, $50 \mathrm{mg}$ of protein extract was mixed with sample loading buffer, kept in water bath at 60 to $65^{\circ} \mathrm{C}$ for $2 \mathrm{~min}$ and electrophoresed on $15 \%$ of separating gel and 4\% stacking gel mix (Pandiarajan, et al., 2011). The SDS - PAGE gel was stained with Coomassie Brilliant Blue R-250 for six hour. Washed the gel twice 
with the double distilled water and kept in a destaining solution for the appearance of bands in the gel.

\section{6) In-gel protein digestion}

The identified band in SDS-PAGE gel was excised; destaining was carried out with methanol and incubated with $200 \mathrm{mM}$ ammonium bicarbonate. Dehydration of the gel was done with acetonitrile solution, dried under vacuum followed by rehydration and tryptic digestion.

\section{7) Protein Identification by (MALDI-TOF) \& Bioinformatics analyses}

In-gel Trypsin digestion and Mass spectrometry analysis was performed in the Molecular Biophysics Unit, IISC, Bangalore, India. The $\mathrm{m} / \mathrm{z}$ ratio peaks obtained from the MALDI MS analysis was subjected to online MASCOT search software tool (Matrix Science Inc., Boston, U.S.A.) to obtain the peptide sequences. The search parameters were set as following, the fixed modification is set to carbamidomethyl $\mathrm{C}$ (Cysteine) and variable modification is set to oxidized M (Methionine), missed trypsin cleavage site is set to 1 .

In the mascot search engine, predicted protein should significant with a p-value less than 0.05. Identified sequences were searched against with Drosophila organisms in Swissprot database sequence for the functions detection. Vectorbase database and BLAST server was used to validate the protein and the protein interactions were predicted by using STRING database.

\section{RESUlts AND Discussion}

The primary phytochemical screening of the methanolic extract of the Aegle marmelos leaves showed the presence of various primary and secondary metabolites in the extract such as protein, phenols, tannins, steroids and titerpene compounds. The current study indicates that the most active ingredient isolated can be act as a best larvicidal agent against the third instar larvae of Aedes aegypti and also showed development distortion. This insect feed on these secondary metabolites encountering toxic substances with non-specific effects on molecular targets and in turn affects physiology in many different ways at different receptor sites (Ghosh et al., 2012).. High level mortality was noticed in the Aegle marmelos and which may be due to the phytochemicals in the extracts which arrests the metabolic activities of larvae. The larvicidal efficacy of A. marmelos against the Aedes aegypti third instar larvae was fixed at 50,100, 150, 200 and $250 \mathrm{ppm}$. The highest toxicity in the bioactive compounds observed at 24 hours Lc50 values are 59 and 49 and at 48 hours Lc90 values are $114 \mathrm{ppm}$ and $108 \mathrm{ppm}$ respectively (Table 1 ).

Table 1: Larvicidal Toxicity of Aegle marmelos methanol leaf Extract The Dengue Vector, Aedes aegypti

\begin{tabular}{|c|c|c|c|c|c|c|c|c|c|c|c|c|}
\hline & \multicolumn{5}{|c|}{ Per cent Mortality (ppm) } & \multirow{2}{*}{$\begin{array}{l}\text { Lc50 } \\
(\mathbf{p p m})\end{array}$} & \multirow{2}{*}{$\begin{array}{c}95 \% \\
\text { (LCL-UCL) }\end{array}$} & \multirow{2}{*}{$\begin{array}{l}\text { Lc90 } \\
(\mathbf{p p m})\end{array}$} & \multirow{2}{*}{$\begin{array}{c}95 \% \\
\text { (LCL-UCL) }\end{array}$} & \multirow[b]{2}{*}{ Slope $\pm \mathbf{S E}$} & \multirow{2}{*}{$\chi^{2}(\mathrm{df}=3)$} & \multirow[b]{2}{*}{ Reg. equation } \\
\hline & 50 & 100 & 150 & 200 & 250 & & & & & & & \\
\hline $24 \mathrm{hr}$ & 08 & 32 & 60 & 88 & 96 & 59 & $50.56-68.11$ & 114 & $95.95-150.97$ & $4.504 \pm .682$ & $2.23^{*}$ & $y=0.928 x-12.8$ \\
\hline $48 \mathrm{hr}$ & 20 & 44 & 68 & 88 & 100 & 49 & $39.68-57.39$ & 108 & $88.11-150.59$ & $3.711 \pm .592$ & $3.82 *$ & $y=0.816 x+2.8$ \\
\hline
\end{tabular}

Control-Nil mortality, UCL \& LCL - Upper \& Lower confidence Limit, $X^{2}$ - Chi-square value, df - degrees of freedom, *Significant at P < 0.05 level.

No significant mortality for control assays. The methanol leaf extract of Aegle marmelos treated larvae revealed the damage disruption around the midgut The midgut region was completely disrupted with shrunken bodies. Thus this extract obviously led to disruptions in growth of Ae. aegypti third instar larvae. A. pinnata might have contributed in body effects of larvae and their study indicated that the potential application of this plant phytochemicals as mosquito larvicidal agent (Zulkrnin et al., 2018). The S. terebinthifolius plant derived bioactive compounds have been reported for larvicidal effects in the mosquito midgut (Procópio et al., 2015), similar to the Aegle marmelos leaf extract. The damage to midgut cells of Ae. aegypti larvae caused by the Aegle marmelos methanol leaf extract may have digestive dysfunction in the larval midgut, and distortion in the growth of larval development.
Primarily, the A. marmelos treated larvae midgut protein sample was quantified using Bradford method BSA as standard (Table 2) and the quantification of protein was plotted in the Fig.1. Ae. aegypti midgut protein of larvae was analyzed quantitatively by using Colorimeter and the OD value was measured at $595 \mathrm{~nm}$. The present investigation showed that the protein concentration was found to vary in the treated and untreated Ae. aegypti midgut proteins. The mean protein concentration was effectively recorded for both untreated larvae $(1237.2 \mu \mathrm{g} / \mathrm{mL})$ and Aegle marmelos leaf extract treated larvae $(1078.6 \mu \mathrm{g} / \mathrm{mL})$. In the present study, total protein content was significantly higher in untreated larvae than the Aegle marmelos leaf extract treated. The results showed that concentration of protein seen higher in untreated larvae reflects a high rate of protein synthesis in the control. Thus, the present findings suggest that there is a disruption taking within the midgut protein 
synthesis. Ratten (2010) reviewed the mode of action of secondary metabolites on insect body and documented several physiological disruptions.

Table 2 Quantification of Aegle marmelos treated Ae. aegypti midgut protein by Bradford's method

\begin{tabular}{|c|c|c|c|c|c|}
\hline $\begin{array}{l}\text { Test } \\
\text { tube }\end{array}$ & $\begin{array}{l}\text { Conc. } \\
\mu \mathrm{g} / \mathrm{ml}\end{array}$ & $\begin{array}{c}\text { BSA } \\
(\mu 1)\end{array}$ & $\begin{array}{l}\text { Distilled } \\
\mathbf{H}_{2} \mathbf{0}(\mu \mathrm{l})\end{array}$ & & $\begin{array}{c}\text { OD } \\
(595 \mathrm{~nm})\end{array}$ \\
\hline S1 & 10 & 100 & 1900 & \multirow{7}{*}{ 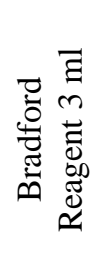 } & 0.035 \\
\hline $\mathrm{S} 2$ & 20 & 200 & 1800 & & 0.662 \\
\hline S3 & 30 & 300 & 1700 & & 0.695 \\
\hline S4 & 40 & 400 & 1600 & & 1.466 \\
\hline S5 & 50 & 500 & 1500 & & 1.864 \\
\hline $\mathrm{T} 1$ & 1237.2 & 100 & 1900 & & 1.116 \\
\hline $\mathrm{T} 2$ & 1078.6 & 100 & 1900 & & 0.978 \\
\hline
\end{tabular}

S1 to, S5 - Standard protein BSA; T1-Untreated; T2-Treated with Aegle marmelos; Control: $5 \mathrm{ml}$ Bradford's reagent;

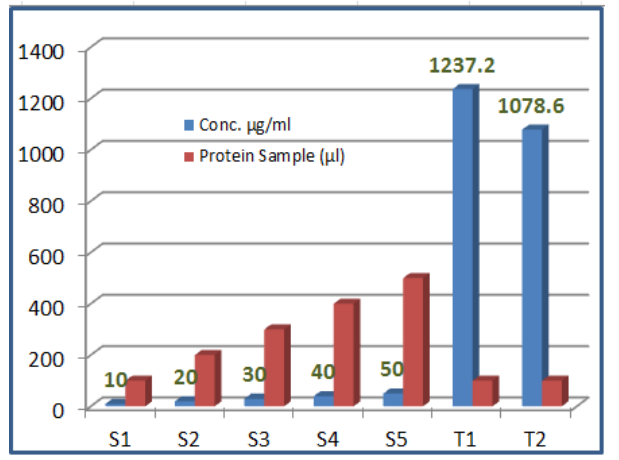

Fig. 1 Aegle marmelos treated Ae. aegypti third instar larvae midgut protein quantified by Bradford's method

In this study, the proteomic analysis of Aedes aegypti third instar larvae midgut was evaluated after treated with various concentrations of Aegle marmelos leaf extract that kills the larvae at $48 \mathrm{hrs}$ of incubation. To know the peptide responsible for the larvae structure modification, we decided to separate the midgut protein extract in $15 \%$ SDS-PAGE. The size of the band obtained in the gel was between 20 to $66 \mathrm{kDa}$ in range. This result is corroborated with (Abbas et al., 2013), they reported that six protein bands were identified ranged from 16.6 to $75 \mathrm{kDa}$ in molecular weight.

Previous studies of midgut epithelial cell structure and function have revealed some information on the cell types defined in D. melanogaster are also established in Ae. aegypti (Fernandes et al., 2014). The pathway induced in midgut of DENV2-primered mosquitoes were identified as Notch transcription (Serrato et al., 2018) and it is an important defensive mechanism against dengue virus infection. The $57 \mathrm{kDa}$ protein possesses dengue viral binding protein property and it has proven by previous studies in the Aedes midgut. The DS3 strains of Ae. aegypti total purified protein resolved in SDS showed that they were in the range of 57 and $67 \mathrm{kDa}$ (Muñoz et al., 2013). Based on this, we also focused on the $\sim 57 \mathrm{kDa}$ fragment was eluted from the SDS-PAGE gel (Fig. 2) exposed to MALDI-MS analysis followed by tryptic digestion and the chromatogram results displayed in the Fig. 3.

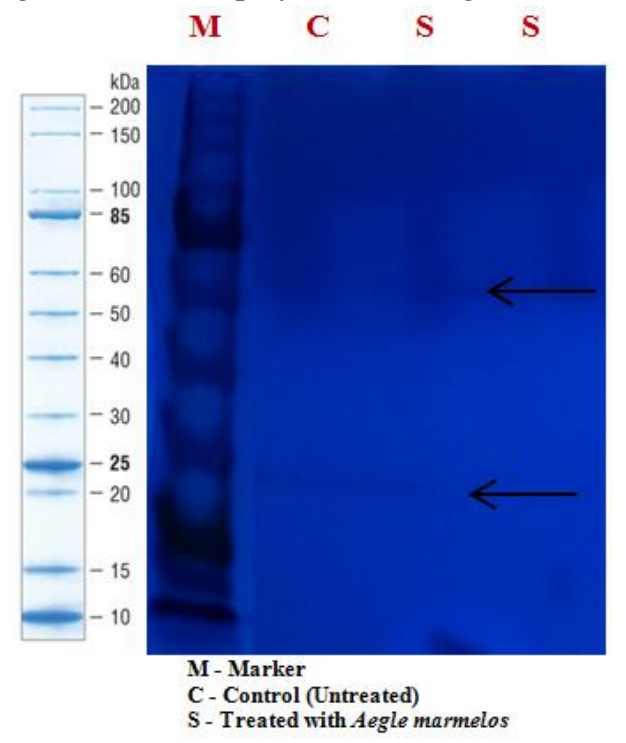

Fig. 2: Protein profile of Aegle marmelos methanol leaf extracts treated and untreated Aedes aegypti Midgut.

Mosquito midgut proteins were separated by SDS-PAGE with $C B B$ stained gel. On the right side, shows molecular weights of the proteins and the left shows marker protein.

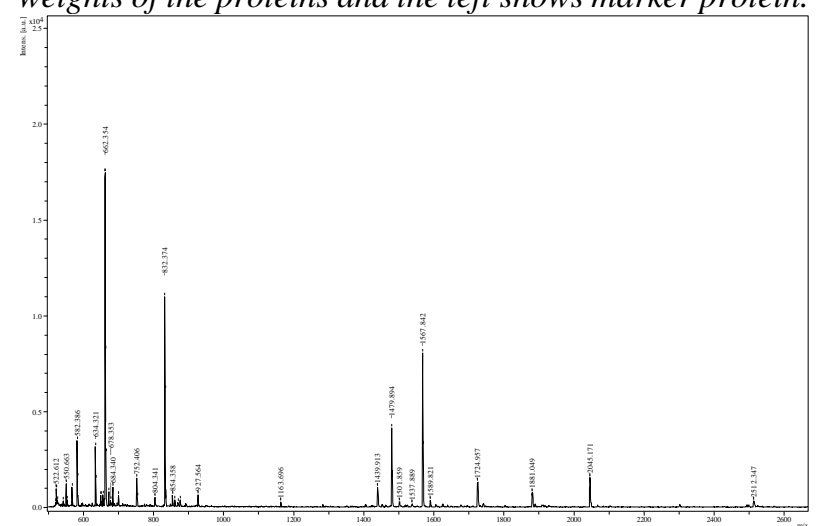

Fig. 3 MALDI MS tryptic digested peptide of Aedes aeygpti midgut protein treated by Aegle marmelos plant extract and the peptide masses were used for protein database searches

The peptide masses list were searched against the protein sequence database, and predicted protein as the product of gene Cyp313a1 of cytochrome P450 sequence of Drosophila melanogaster which is a $56 \mathrm{kDa}$ protein (Fig.4). The experimentally determined seventeen masses cover only 17 per cent of the protein sequence. Table 3 shows the observed and calculated masses of peptide and their sequence assignments. Among the 17 peptide masses identified, 8 peptides covered in the predicted protein Drosophila sequence. 
The obtained sequence was compared with the non-redundant protein sequence database specified with the Aedes aegypti organism using BLASTP software.

The results confirmed that the predicted protein belongs to Aedes aegypti cytochrome P450 sequence with 42 per cent identity Fig. 5.1 to 5.3. Further, the longest matched peptide as query sequence in fasta format (NCIGSKYAMMSSKFALCR) was subjected to a Vectorbase BLASTP tool for similar sequence identification from Aedes species sequences stored. The analysis was based on Vectorbase database Ae. aegypti sequences and related similarity. Interestingly the query is also perfectly aligned with the eight cytochrome P450 peptides of Aedes aegypti sequences with more than 55 per cent identity and score. Among these, four peptide sequences AAEL012772-PA, AAEL017136-PB, AAEL012766-PA and AAEL003748-PA showed biologically significant result once viewed their E-values (Table 4). By mascot searches, Muñoz et al. (2013) identified the $57-67 \mathrm{kDa}$ proteins were enolase, beta-ARK, translation elongation factor EF-1 alpha/ Tu and cadherin. Peptide Mass Fingerprint data analysis couldn't show the same mass of different peptides (Sechi and Chait, 1998; He et al., 2008).

But the protein identified by this current study does not match with any other Aedes aegypti midgut proteins studied so far this means that the Aegle marmelos plant leaf extract might altered or influence the protein present in the midgut membrane. The total mass chromatogram of Aedes aegypti third instar larvae treated with Aegle marmelos plant leaf extract midgut proteins obtained, after that MALDI/MS spectrum of mascot search identified four upregulated proteins with Drosophila melanogaster are AT-rich binding protein, Bomanin, Accessory gland-specific peptide and Eukaryotic translation initiation factor at peaks 662.354 , $832.374,1479.894 \& 1567.842 \mathrm{~m} / \mathrm{z}$ respectively (Table 5). Structural and functional networks of protein-protein interactions of identified proteins were analyzed and predicted using STRING 11 analysis software. STRING analysis can be used to understand the cellular machinery at the system level and this information can be implicated in modeling, annotation and pathway studies (Fig. 6).

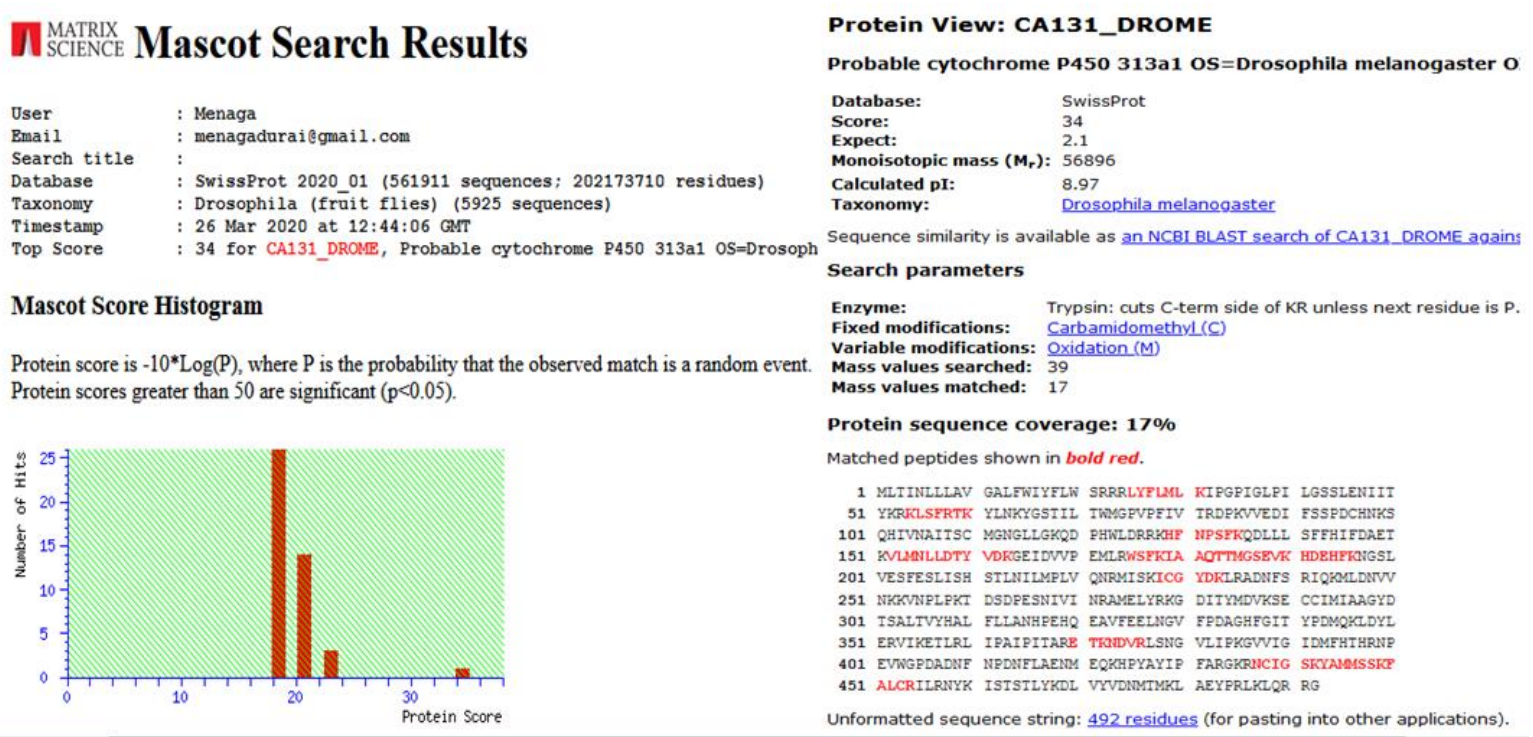

Fig. 4 MALDI peptide masses analyzed by Mascot server against Swissprot database shows that the predicted protein has 17\% sequence coverage with Drosophila Cytochrome P450; Matched peptide sequences shown in bold red

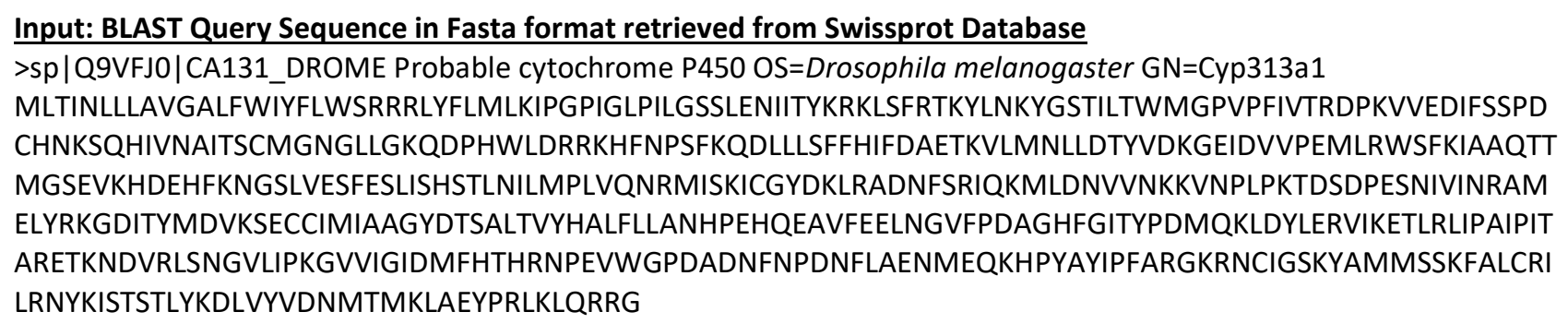


International Journal of Research in Advent Technology, Vol.8, No.6, June 2020

E-ISSN: 2321-9637

Available online at www.ijrat.org

Table 3: Molecular Masses for Tryptic Peptides Identified from MALDI Search against Mascot server for the Aedes aegypti Midgut protein Treated with Aegle marmelos plant extract

\begin{tabular}{|c|c|c|c|c|c|c|}
\hline \multirow[b]{2}{*}{ Observed } & \multicolumn{2}{|c|}{$\operatorname{Mass}\left(\mathbf{D a}^{\mathbf{b}}\right)$} & \multicolumn{2}{|c|}{$\begin{array}{c}\text { Seq. } \\
\text { position }\end{array}$} & \multirow[b]{2}{*}{$\mathbf{M}$} & \multirow[b]{2}{*}{ Peptide Sequence $^{a}$} \\
\hline & Expected & Calculated & Start & End & & \\
\hline 522.612 & 521.6047 & 521.2962 & 55 & 58 & 0 & K.LSFR.T \\
\hline 568.172 & 567.1647 & 566.2853 & 175 & 178 & 0 & R.WSFK.I;K.IAAQTTM'GSEVKHDEHFK.N \\
\hline 650.079 & 649.0717 & 649.3911 & 54 & 58 & 1 & R.KLSFR.T \\
\hline 651.298 & 650.2907 & 649.3911 & 54 & 58 & 1 & R.KLSFR.T \\
\hline 666.075 & 665.0677 & 665.3319 & 450 & 454 & 0 & K.FALCR.I \\
\hline 678.353 & 677.3457 & 677.3166 & 437 & 442 & 0 & R.NCIGSK.Y \\
\hline 752.406 & 751.3987 & 750.4388 & 55 & 60 & 1 & K.LSFRTK.Y \\
\hline 754.396 & 753.3887 & 754.332 & 228 & 233 & 0 & K.ICGYDK.L \\
\hline 832.374 & 831.3667 & 832.3459 & 443 & 449 & 0 & K.YAMM'SSK.F \\
\hline 861.133 & 860.1257 & 860.4352 & 370 & 376 & 1 & R.ETKNDVR.L \\
\hline 876.344 & 875.3367 & 875.429 & 129 & 135 & 0 & K.HFNPSFK.Q \\
\hline 927.564 & 926.5567 & 926.5299 & 25 & 31 & 0 & R.LYFLM'LK.I \\
\hline 1439.913 & 1438.9057 & 1438.7378 & 152 & 163 & 0 & K.VLM'NLLDTYVDK.G \\
\hline 1479.894 & 1478.8867 & 1479.6672 & 443 & 454 & 1 & K.YAMM'SSKFALCR.I \\
\hline 2045.171 & 2044.1637 & 2043.9684 & 179 & 196 & 1 & K.IAAQTTMcGSEVKHDEHFK.N \\
\hline
\end{tabular}

Table 4 : Similarity Search of Cyt P450 mascot predicted protein against the Aedes aegypti Sequence database at Vectorbase (Aegle marmelos Treated)

Blast Query for Vectorbase :

$>$ Cyt $\mathbf{P 4 5 0}$ peptide(fasta)

NCIGSKYAMMSSKFALCR

\begin{tabular}{ccccc}
\hline Similar Peptide & Gene & E-value & Score & Identity \\
\hline AAEL012772-PA & CYP325G3 & 0.023 & 68 & $70.60 \%$ \\
AAEL000320-PA & CYP325T1 & 0.36 & 59 & $68.80 \%$ \\
AAEL017136-PB & CYP325V1 & 0.053 & 65 & $66.70 \%$ \\
AAEL012766-PA & CYP325G2 & 0.096 & 63 & $64.70 \%$ \\
AAEL006044-PA & CYP325Q1 & 0.28 & 60 & $62.50 \%$ \\
AAEL003748-PA & CYP9AE1 & 0.045 & 66 & $61.10 \%$ \\
AAEL005775-PA & CYP325R1 & 0.53 & 57 & $56.30 \%$ \\
AAEL007812-PA & CYP4H32 & 0.46 & 58 & $55.60 \%$ \\
\hline
\end{tabular}

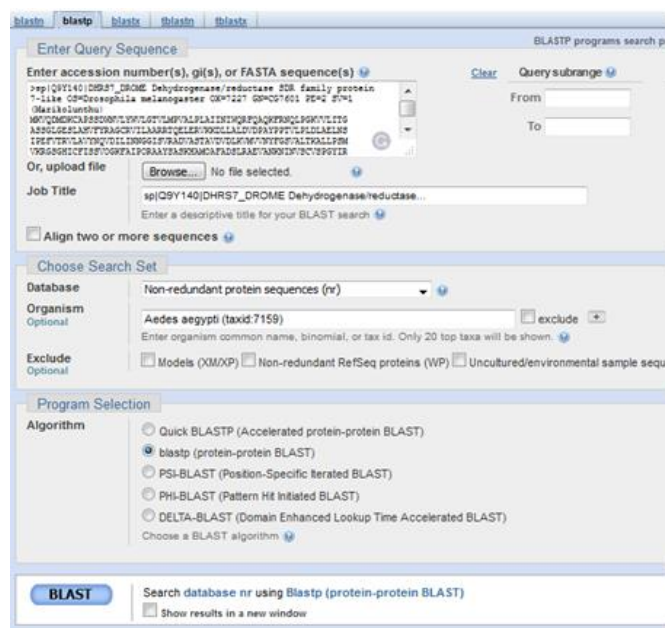

BLAST ${ }^{\circ}$ » blastp suite » results for RID-8VCDUM2M016

\begin{tabular}{|c|c|}
\hline <Edit Search & Search Summary $\vee$ \\
\hline \multicolumn{2}{|c|}{ (1) Your search is limited to records that include: Aedes aegypti (taxid:7159) } \\
\hline Job Title & sp|Q9VFJ0|CA131_DROME Probable cytochrome... \\
\hline RID & 8VCDUM2M016 Search expires on 04.09 19:12 pm Download All \\
\hline Program & BLASTP $?$ Citation $v$ \\
\hline Database & $\mathrm{nr}$ seedetails $v$ \\
\hline Query ID & Icl|Query_31682 \\
\hline Description & Sp|Q9VFJ0|CA131_DROME Probable cytochrome P450313a1 ... \\
\hline Molecule type & amino acid \\
\hline Query Length & 492 \\
\hline Other reports & Distance tree of results Multiplealignment MSA viewer 2 \\
\hline
\end{tabular}

Fig. 5.1 Setting up of BLASTP search of the protein sequence predicted by MALDI Mascot search against the NCBI Aedes Aegypti (taxid:7159) organism Non-redundant Protein sequence database 
International Journal of Research in Advent Technology, Vol.8, No.6, June 2020

E-ISSN: 2321-9637

Available online at www.ijrat.org

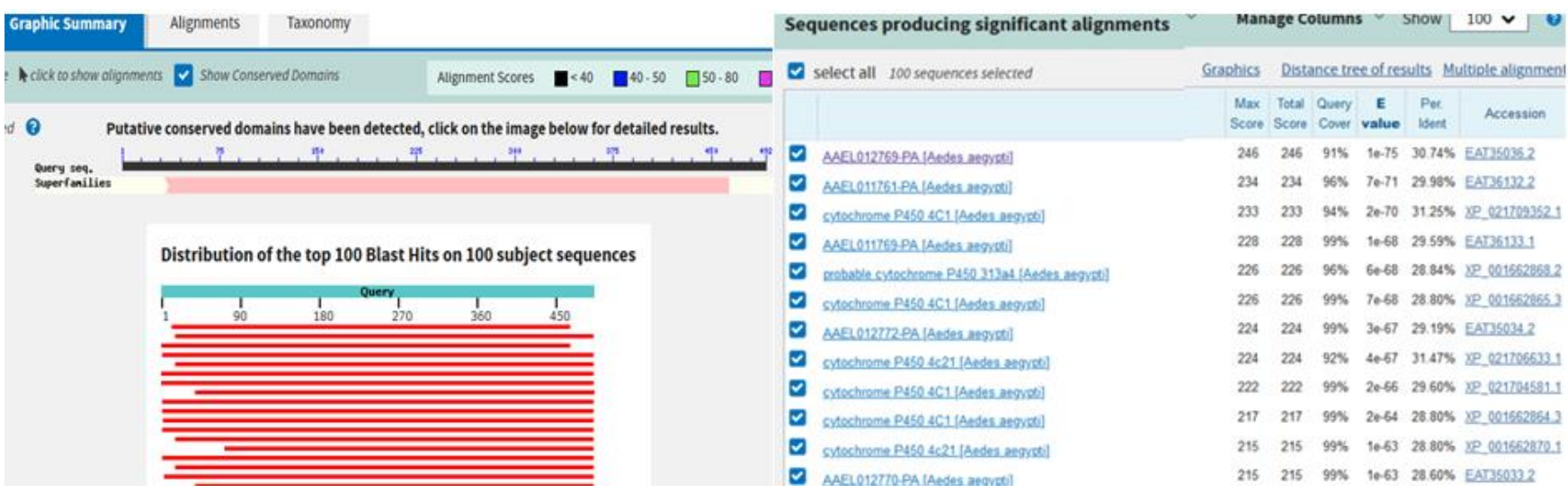

Fig. 5.2 BLASTP Output: a) Query details; b) A Graphical overview of all the similar sequences;c) List of BLASTP hits that produce significant alignments with our query sequence and contains links to the NCBI databases

\begin{tabular}{|c|c|c|c|}
\hline Alignment view & Pairwise & (2) & \\
\hline \multicolumn{4}{|c|}{100 sequences selected } \\
\hline \multicolumn{4}{|c|}{ ¿ Download $\sim$ GenPept Graphics } \\
\hline \multicolumn{4}{|c|}{ probable cytochrome P450 $313 \mathrm{a2}$ [Aedes aegypti] } \\
\hline \multicolumn{4}{|c|}{ Sequence ID: XP_021709972.1 Length: 196 Number of Matches: 1} \\
\hline \multicolumn{4}{|c|}{ Range 1: 3 to 195 GenPept Graphics } \\
\hline $\begin{array}{l}\text { Score } \\
160 \text { bits(405) }\end{array}$ & $\begin{array}{ll}\text { Expect Method } & \text { Identities } \\
2 \mathrm{e}-46 \text { Compositional matrix adjust. } & 81 / 195(42 \%)\end{array}$ & $\begin{array}{ll}\text { Positives } & \text { Gaps } \\
119 / 195(61 \%) & 2 / 195(1 \%)\end{array}$ & \\
\hline Query 297 & 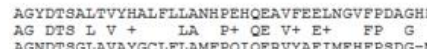 & 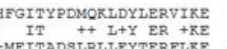 & 356 \\
\hline Query 357 & TLRLIPAIPITARETRNDVRLSNGVLIPRGVVIGIDMFHT: & FHRNPEVWGPDADNFNPDNFL & 416 \\
\hline sbjet 62 & 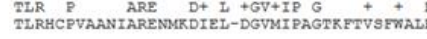 & $\begin{array}{l}\text { MR ++WGP+ +F+PD+FE } \\
\text { HRRRADMTGPEHSFDPDFE }\end{array}$ & 120 \\
\hline Query 417 & 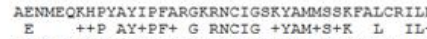 & 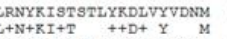 & 476 \\
\hline Sbjet 121 & PERCRDRNPNAYMP FSTGARNCIGGRYMMLSTRVMLIHIL & UKNFRITTKLRFEDMRYKFGM & 180 \\
\hline Query 477 & $\begin{array}{l}\text { TMRLAEYPRLRLORR } \\
\mathrm{T}+\mathrm{K}++ \\
++\mathrm{I}+\mathrm{RR}\end{array}$ & & \\
\hline sbjet 181 & TLRMSTDHLVQLERR 195 & & \\
\hline
\end{tabular}

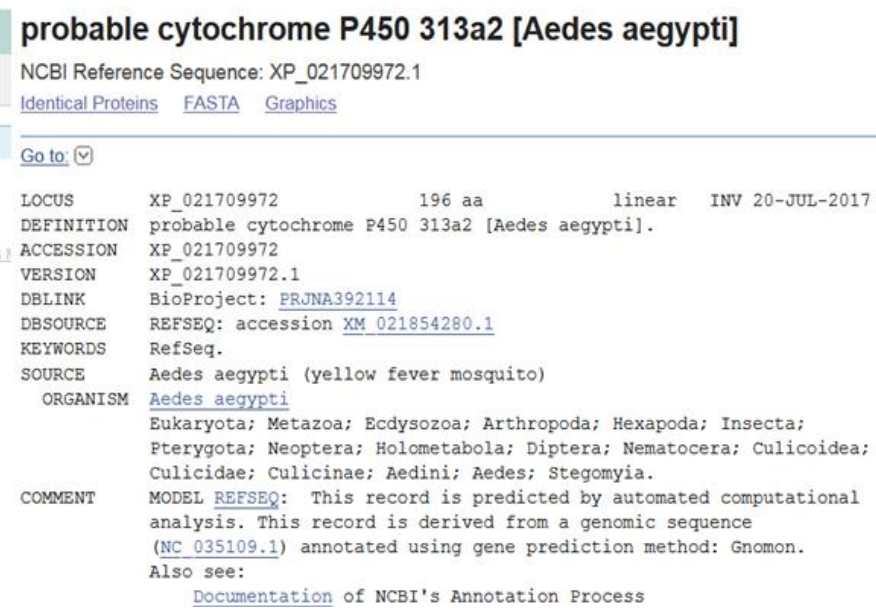

Fig. 5.3 a) BLASTP alignment between the peptide sequence predicted (Query) with the Aedes aegypti Cytochrome P450 sequence (Sbjct); b) Aedes aegypti Cytochrome P450 retrieved from NCBI Sequence database

Table 5: Peptides identified as up-regulated in midgut of Aegle marmelos treated Ae. aegypti larvae

\begin{tabular}{|c|c|c|c|c|c|}
\hline $\begin{array}{l}\text { Peptide mass } \\
\text { (Da) }\end{array}$ & Peptide sequence & $\begin{array}{c}\text { Similar Sequence } \\
\text { Drosophila melanogaster }\end{array}$ & Score & $\begin{array}{l}\text { Sequence } \\
\text { coverage }\end{array}$ & pI \\
\hline 662.354 & FKYKSRMELHRVVHSKER & AT-rich binding protein & 57 & $5 \%$ & 6.75 \\
\hline 832.374 & K.VCNIRGD & $\begin{array}{l}\text { Bomanin-068 - immune-induced } \\
\text { peptide toll signalling }\end{array}$ & 19 & $17 \%$ & 7.82 \\
\hline 1479.894 & R.KPTKFPIPSPNPR.D & Accessory gland-specific peptide & 19 & $23 \%$ & 10.1 \\
\hline 1567.842 & K.GNDDDIQDGLVHIR.I & EK Translation initiation factor & 17 & $12 \%$ & 6.82 \\
\hline
\end{tabular}




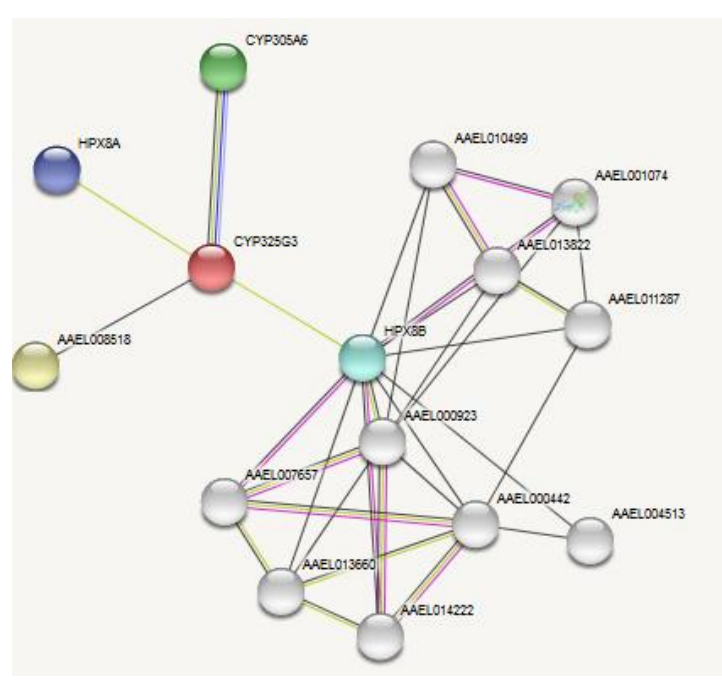

Fig. 6 STRING PPI network of Cytochrome $\mathbf{P 4 5 0}$ protein identified in the of Aegle marmelos Treated Ae. Aegypti larvae midgut. ID numbers denote sequence accession numbers in the Swissprot. Interaction networks are shown in the confidence view with color lines.

Green colour depicts neighbourhood; Red colour: Gene fusion; Pink colour:Experiments; Light green colour: Text mining; Blue colour:Cooccurrence; Dark blue colour: Coexpression; Purple colour:Homology; and circle nodes indicated different proteins. Interaction networks are shown in evidence view

The available association network was studied for the protein, i.e. AAEL012772-PA (Cytochrome P450) matched with monooxygenase and Heme peroxidase has homologs with Aedes, Culex and Anopheles species with the p-value of 0.566. Detailed functional analysis of these proteins was carried out using GO and other bioinformatics algorithms. The biological process of the identified peptide involved in oxidation-reduction process and the molecular function depicts the monooxygenase activity.

The xenobiotics reduction or oxidation process of cytochrome P450 monooxygenase (CYP) gene was studied (Saavedra et al., 2014) and it's represented in Aedes aegypti detoxification genes. P450s are involved in drug metabolism (Werck and Feyereisen, 2000) and insecticide resistance. The pyrethroid influence in CYP4 expression may cause adverse effect in A. albopictus (Avicor et al., 2014). Ilango et al. (2007) reported that C-methylated flavone from C. lanceolatus is responsible for the larvicidal activity. The active compounds identified will play a role in developmental duration of the mosqutoes such as $C$. quinquefasciatus and A. stephensi (Ilango et al., 2016).

\section{Conclusion}

At present, there is no potent medicine for dengue making the laboratory oriented investigation system is an important need and an essential tool to control the Aedes aegypti mosquito vector control and also environmental friendly. Dengue virus replication mainly occurs in mosquito midgut and plays a mail role in the transmission of this disease to humans. Ecofriendly, cost effective control of this mosquito by natural bioactive compound is necessary. In-silico proteomic analysis is essential for developing novel vector control strategies, and to identify dengue viral protein receptors on the midgut which will help in future research. In conclusion, our study revealed that Aegle marmelos leaf extract had potencial application as larvicide.

The computational proteomic analysis highlights the potential effect of Aegle marmelos leaf extract against the Ae. aegypti third instar larvae and exhibited an induction of structural disorganization in the midgut epithelial cells. The identified phytochemicals and their ability to control this vector species is either by their insecticidal property or by growth disruption. These phytoextracts could be purified further and used as biological insecticides instead of synthetic chemicals, which currently is the major means of mosquito vector control and also environmental friendly. Further studies will be indispensable to validate the pharmacological properties and make potent drug at cheap cost from of natural phytochemicals.

\section{CONFLICT OF INTEREST}

The authors declare that they have no conflict of interests.

\section{ACKNOWLEDGMENT}

The authors magnanimously thank TNSCST, Tamil nadu for providing financial support to carry out this work under SPS Scheme. We also thank the Management and Principal, Ayya Nadar Janaki Ammal College, Sivakasi for provided great support by making the availability of various institutional facilities.

\section{REFERENCES}

[1] M. G. Guzman, S. B. Halstead, H. Artsob, P. Buchy, J. Farrar, D. J Gubler, E. Hunsperger, A. Kroeger, H. S. Margolis, E. Martínez, M. B. Nathan, J. L. Pelegrino, C. Simmons, S. Yoksan and W. P. Rosanna, Dengue: a continuing global threat", Nature Reviews: Microbiology, vol. 8, pp. S7- S16, 2010.

[2] G. Ekta and B. Neha, "Current perspectives on the spread of dengue in India", Infection and Drug Resistance, vol. 7, pp. 337-342, 2014.

[3] A. Ghosh, N. Chowdhury and G. Chandra, "Plant extracts as potential mosquito larvicides", Indian J. Med. Res., vol. 135, no. 5, pp. 581-598, 2012.

[4] S. Idrees and U. A. Ashfaq, "RNAi: antiviral therapy against dengue virus", Asian Pacific Journal of Tropical Biomedicine, vol. 3, no. 3, pp. 232-236, 2013.

[5] N. P. Atul, V. D. Nilesh, A. R. Akkatai and S. K. Kamlakar, "A review on Aegle marmelos: a potential medicinal tree", International Research Journal of Pharmacy, vol. 3, no. 8, pp. 86-91, 2012.

[6] F. H. Stephenson, "Calculations for Molecular Biology and Biotechnology", 2nd Ed., London : Academic Press publications, 2010, 385-388.

[7] S. R. Whiten, W. K. Ray, R. F. Helm and Z. N. Adelman, "Characterization of the adult Aedes aegypti early midgut peritrophic matrix proteome using LC-MS", PloS one, vol. 13, no. 3, e0194734, 2018. 
[8] K. George, B. Jayaprakasam, S. S. Dalavoy and M. G. Nair, "Pest-managing activities of plant extracts and anthraquinones from Cassia nigricans from Burkina Faso", Bioresour. Technol., vol. 99, no. 6, pp. 2037-2042, 2008.

[9] WHO: Guidelines for Laboratory and Field Testing of Mosquito Larvicides. World Health Organization Communicable Disease Control, Prevention and Eradication, WHO Pesticides Evaluation Scheme, 2005

[10] W. S. Abbott, "A method for computing the effectiveness of an insecticide", J Econ Entomol., vol. 18, pp. 265-267, 1925.

[11] D. J. Finney, "A statistical treatment of the sigmoid response curve. In: Probit analysis". Cambridge University Press, London. pp. 633. 1971.

[12] L. H. English and T. L. Reddy, "Delta endotoxin inhibits a phosphatase in midgut epithelial membranes of Heliothis virescens", Insect Biochem., vol.19, pp. 145-152, 1989.

[13] A. P. Butler and D. H. Deana, "Proteomic analysis of the mosquito Aedes aegypti midgut brush border membrane vesicles", J Insect Physiol., vol. 55, no. 3, pp. 264-272, 2014.

[14] M. M. Bradford, "A rapid and sensitive method for the quantitation of microgram quantities of protein utilizing the principle of a protein-dye binding", Anal. Biochem., vol. 72, pp. 248-254, 1976.

[15] U. K. Laemmli, "Cleavage of structural proteins during the assembly of the head of bacteriophage T4", Nature, vol. 227, pp. 680-685, 1970.

[16] J. Pandiarajan, P. C. Britto, T. Pratheep and Krishnan M., "Defense role of the cocoon in the silk worm Bombyx mori L.", Rapid Commun. Mass Spectrom., vol. 25, pp. 3203-3206, 2011.

[17] H. Zulkrnin, N. Shaida and N. N. Rozhan, "Larvicidal effectiveness of Azolla pinnata against Aedes aegypti (Diptera: Culicidae) with its effects on larval morphology and visualization of behavioural response," Journal of Parasitology Research, Article ID 1383186, 5 pages, 2018.

[18] T. F. Procópio, K. M. Fernandes, E. V. Pontual, R. M. Ximenes, A. R. C. Oliveira, C. S. Souza, "Schinus terebinthifolius Leaf Extract Causes Midgut Damage, Interfering with Survival and Development of Aedes aegypti Larvae", PloS one, vol. 10, no. 5, e0126612, 2015.

[19] R. S. Ratten, Mechanism of action of insect secondary metabolites of plant origin, Crop Protect, vol. 29, pp.913-920, 2010.

[20] A. Abbas, M. Khalid. A. Ghamdi, M. A. Shaheen and A. A. Zaituon, "Protein Analysis of Dengue Fever Vector Aedes aegypti, using SDS-PAGE in Jeddah Governorate-Saudi Arabia”, Biosciences Biotechnology Research Asia, vol. 10, no. 1, pp. 89-94, 2013.

[21] K. M. Fernandes, C. A. N. Serro and G. F. Martins, "Aedes aegypti midgut remodeling during metamorphosis", Parasitology, vol.63, pp. 506-512, 2014.

[22] S. J. Serrato, J. Izquierdo-SaÂnchez, M. ArguÈello, R. Conde, A. Alvarado-Delgado, H. Lanz-Mendoza, "Aedes aegypti Antiviral Adaptive Response Against DENV-2”, Dev Comp Immunol, vol. 23, pp. 456-467, 2018.

[23] M. Muñoz, G. Limón-Camacho, R. Tovar, A. Diaz-Badillo, G. Mendoza-Hernández, and W. C. Black, "Proteomic identification of dengue virus binding proteins in Aedes aegypti mosquitoes and Aedes albopictus cells", BioMed Research International, pp.875958, 2013.

[24] S. Sechi and B. T. Chait, "Modification of cysteine residues by alkylation - A tool in peptide mapping and protein identification", Anal. Chem., vol. 70, no. 24, pp. 5150-5158, 1998.

[25] Z. He, C. Yang and W. Yu, "Peak bagging for peptide mass fingerprinting", Bioinformatics, vol. 24, pp. 1293-1299, 2008.

[26] K.Saavedra-Rodriguez, C. Strode, A.E. Flores, S. Garcia-Luna, G. Reyes-Solis, H. Ranson, J. Hemingway, W.C. Black, "Differential transcription profiles in Aedes aegypti detoxification genes after temephos selection”, Insect Mol Biol, vol. 23, no. 2, pp. 199-215, 2014.

[27] D. Werck-Reichhart and R. Feyereisen, "Cytochromes P450: a success story", Genome Biol., vol. 1, no. 6, pp.3003-3006,2000.

[28] S. W. Avicor, M. F. Wajidi, F. M. Elgarj, Z. Jaal and Z. S. Yahaya, "Insecticidal activity and expression of cytochrome P450 family 4 genes in Aedes albopictus after exposure to pyrethroid mosquito coils", Protein J., vol. 33, no. 5, pp. 457-464, 2014.

[29] S. Ilango, J. Muthukrishnan, P. Gunasekaran and S. Kandula "Plant products inhibit the larval and adult emergence of Culex quinque fasciatus and Anopheles stephensi”, Inter. J. Environ. Soc. Sci., vol.2, pp. 59-68, 2007.

[30] S.Ilango, D. Athirstalaxmi and M. Malarvizhi, "Effects of phytochemicals on fecundity and hatchability of Culex quinquefasciatus and Anopheles stephensi”, Int. Res. J. Biological Sci., vol. 5, no.3, pp 31-39, 2016.

\section{AUTHORS PROFILE}

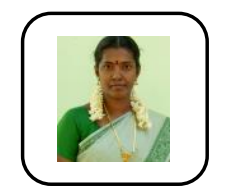

Sugapriya Menaga Paulraj, M.Sc. M.Phil., PGDCA, ADBI is having fourteen years of teaching experience and currently working as Assistant Professor in the Department of Biotechnology and Bioinformatics in Ayya Nadar Janaki Ammal College [Autonomous, CPE, Affiliated to MKU, Re-accredited ( ${ }^{\text {rd }}$ Cycle) with A grade with CGPA 3.67 out of 4.0 by NAAC, DBT STAR College] in Sivakasi, Virudhuunagar district. The author received four TNSCST Projects from the Government of Tamil Nadu and organized Workshops and Seminars on Bioinformatics and Proteomics. 